\title{
A PESQUiSA DO COTIDIANO ESCOLAR PELAS TRILHAS DA FORMAÇÃO DOCENTE: UMA ARTICULAÇÃO UNIVERSIDADE-ESCOLA
}

\author{
INVESTIGACIÓN DE ESCUELA TODOS LOS DÍAS PARA LAS PISTAS DE LA \\ FORMACIÓN DOCENTE: UNA RELACIÓN UNIVERSIDAD-ESCUELA
}

\author{
RESEARCH OF SCHOOL DAILY ROUTINE THROUGH THE PATHS OF \\ TEACHER TRAINING: A UNIVERSITY-SCHOOL RELATIONSHIP
}

\author{
Rita de Cássia Magalhães Trindade STANO1
}

\begin{abstract}
RESUMO: A aproximação universidade-escola faz-se cada vez mais urgente num cenário educacional em que a formação docente está sendo focada pelas políticas públicas de educação. Este artigo apresenta os resultados de uma reflexão a partir dos registros da experiência que vem se desenvolvendo, desde 2013, num Grupo de Trabalho sobre a Pedagogia da Autonomia, em que professores do Ensino Superior e da Educação Básica, bem como alunos-licenciandos(30 participante, em média) compartilham suas práticas docentes tendo como ponto de partida e de chegada o próprio cotidiano escolar.É a efetividade da formação docente continuada por meio de pesquisa do e no cotidiano escolar, num movimento teórico-prático de descotidianização das práticas docentes. Como resultante deste trabalho observa-se a configuração circular entre saberes legitimados pela teoria e saberes advindos da experiência docente, assumindo a centralidade do cotidiano como categoria de investigação-prática importante para o fortalecimento de uma docência construída na colegialidade e na problematização sistemática dos saberes e dos fazeres docentes.
\end{abstract}

PALAVRAS-CHAVE: Docência. Cotidiano escolar. Formação docente. Problematização.

RESUMEN: El enfoque de la universidad y la escuela es cada vez más urgente en un entorno educativo en el que la formación del profesorado está siendo enfocada por las políticas de educación pública. Este artículo presenta los resultados de una reflexión a partir de los registros de experiencia que se viene desarrollando desde 2013 un Grupo de Trabajo sobre la Pedagogía de la autonomía, donde los profesores de la educación superior y la educación básica, así como estudiantes de pregrado (30 participante en promedio) compartir sus prácticas de enseñanza que toman como punto de partida y de llegada diaria propia escolar.É la eficacia de la formación docente continua a través de la investigación y en la vida cotidiana de la escuela, un movimiento teórico-práctico de descotidianização de las prácticas de enseñanza. Como resultado de este trabajo se observa la configuración circular entre el conocimiento legitimado por la teoría y el conocimiento derivado de la experiencia en la enseñanza, asumiendo la centralidad de la vida cotidiana como una importante investigación y la categoría práctica para

\footnotetext{
${ }^{1}$ Professora Associada da Universidade Federal de Itajubá, do Instituto de Produção e Gestão. Atua como docente no Programa de Mestrado em Educação em Ciências e nas Licenciaturas de Física, Matemática, Química e Biologia. Dirige o curso de especialização a distância em Gestão Educacional. Email: ritastano@gmail.com
} 
fortalecer una enseñanza basada en la colegialidad y el cuestionamiento sistemático de conocimientos y hechos de los maestros.

PALABRAS CLAVE: Enseñanza. Rutina escolar. la formación del profesorado. Cuestionamiento.

ABSTRACT: The university-school approach has become increasingly urgent in an educational setting, where teacher training is being focused by public education policies. This article presents the results of a reflection based on an experience that has been being developed since 2013 by the Working Group on the Pedagogy of Autonomy, where teachers of Higher Education and Basic Education, as well as undergraduates, share their teaching practices analyzing their own school daily routine (30 members on average). It is the effectiveness of continuing teacher training through research of and in school daily life routine, a theoretical-practical moviment of routine discontinuation of teaching practices. As a result of this work it is possible to observe the circular configuration between legitimate knowledge in the theory and knowledge arising from the teaching experience, assuming the centrality of school daily routine as an important research and practical category for the strengthening of a teaching built on collegiality and systematic questioning of knowledge and the teachers' practices.

KEYWORDS: Teaching. School daily routine. Teacher training. Questioning.

\section{Introdução}

Pensar o lugar da pesquisa educacional no percurso de formação continuada docente supõe um redimensionamento da pesquisa, da pesquisa na educação e a localização do cotidiano e o que se entende por cotidiano escolar. A escola, plural e complexa, segundo Alves (2003) apresenta um cenário diverso e ainda não devidamente dimensionado, com a inserção de tecnologias digitais de informação e comunicação em seu cotidiano bem como outros ambientes de aprendizagem que vem desmodelizando papéis e instalando incertezas e novas dificuldades para o exercício da docência.

As indagações acerca do papel da pesquisa do cotidiano escolar e em que sentido o cotidiano escolar se relaciona com a pesquisa educacional que podem integrar a formação continuada docente partem da necessidade de avaliar o contexto de um grupo de pesquisa e extensão em educação que tem se constituído pela aproximação escolauniversidade. Ou seja, tais indagações advém de um movimento entre professores universitários, alunos-licenciandos e professores do Ensino Básico que se caracteriza 
pelo compartilhamento de práticas de ensino, desestabilizando muros epistemológicos e praxiológicos.

Assim, o percurso deste texto se traduz em a) situar a pesquisa na Educação e sua configuração nos sentidos do cotidiano; b) apreender o cotidiano escolar para a formação continuada docente de um grupo de professores; c) identificar o potencial do compartilhamento de práticas docentes sob a perspectiva do cotidiano escolar na relação Universidade-Escola. Pretende-se traçar aqui um percurso que sustente as próprias indagações que tem permeado as inquietações acerca da vinculação teoria-prática; academia-campo de pesquisa; licenciandos-licenciados; pesquisa-cotidiano.

\section{A pesquisa na educação e seus cenários de abrigo no cotidiano}

A Educação, como campo de estudo, se revela, se anuncia e se denuncia por meio da pesquisa, caracteristicamente científica, mas não só. É por meio de um olhar ampliado, de uma escuta cuidadosa e de uma sistematização metodológica que o conhecimento acerca da educação se constrói, se con-firma e se renova. Da necessidade de um conhecimento acerca de elementos quantitativos configuradores do cenário educacional, a partir da década de 70, no Brasil, como questões referentes à evasão, repetência, exclusão-inclusão efetuaram-se as investigações de cunho quantitativo, imprescindíveis para o delineamento das políticas públicas de educação. Tais investigações abarcam, ainda hoje, informações que subsidiam tomadas de decisões e contribuem para uma visualização aproximada do real-educacional posto em números, gráficos, tendências, evoluções e faltas. Entretanto, as pesquisas quantitativas também arriscam-se a criar realidades inquestionáveis, conforme Popkewitz (2013, p. 27) ao destacar que os mecanismos de mensuração “(...) tem o potencial de se materializar como aquilo que é aceito como real em educação" .

A partir dos anos 90, segundo Nunes (2001) outras preocupações provocam indagações acerca do processo educacional que apenas a pesquisa quantificada não consegue responder, bem como outras metodologias vão sendo incorporadas às pesquisas no campo das Ciências Humanas e Sociais, de acordo com André(1992). Assim, num processo inverso, as pesquisas de cunho qualitativo tornam-se centrais para a compreensão do cenário educacional, evidenciando elementos não quantificáveis, pouco tangíveis, porém, constituintes dos mesmos cenários amplos abordados pelas pesquisas quantitativas como a relação entre escola e cultura (CANDAU, 2011). Inicia- 
se um olhar menos geral, mais localizado e refinado que instala-se e movimenta-se nos ambientes escolares, em seus registros, em seus discursos, em suas vozes(caladas ou não)e, enfim, em seus sujeitos.

Deste modo, apreender os sentidos do processo educativo, flagrar a escola como espaço de disputas e tensões, identificar os significados construídos pelos professores e alunos, a qualidade da relação pedagógica são campos deflagradores de indagações que exigem uma outra maneira de olhar e de buscar respostas aos aspectos menos objetivos e materiais e mais subjetivos e imateriais.

É, pois a pesquisa que, ao invés de alçar altos voos, se embrenha e adentra o espaço escolar, considerando cada escola um universo próprio, com mecanismos de gestão e de realização de políticas públicas de currículo e de avaliação materializadas em suas salas de aula, em suas reuniões rotineiras, em seus projetos concebidos e desenvolvidos junto aos alunos e à comunidade local.

Abre-se, via pesquisa, um cenário próximo aos sujeitos da educação(professores, direção, especialistas, alunos, pais, licenciandos-estagiários), porém ainda insuficientemente analisados e compreendidos em suas singularidades e naquilo que tem de universal e comum a todos os cenários escolares. A insuficiência está na amplitude do próprio real-escolar, com suas nuances, seus acontecimentos e suas idiossincrasias que ainda não foram descortinadas pelo olhar-estranhamento necessário à pesquisa. Há neste descortinamento via investigação, processos de aprendizagem, reelaborações de relações de poder, das práticas docentes e dos elementos gestores de opressão e emancipação que precisam ser dilapidados e reconstruídos pela reflexão. A reconstrução de sentidos, pela via da pesquisa, pode colaborar para outras possibilidades de arranjos didático-pedagógicos e caminhos de gestão que podem ser traçados e se tornarem permanentes atualizações do próprio exercício do profissional docente.

A escola, como lugar institucional e legitimado para a realização da educação formal como prática social é o lugar privilegiado para se indagar acerca da docência. Porque é na escola que o professor continua sua própria formação profissional e onde se pode superar a dicotomia característica de qualquer profissionalidade e, em especial do professor, que é a questão teoria e prática (ALVES, 2003). É no espaço escolar, no exercício da docência, que ocorre o enfrentamento da teoria, por meio de uma prática que é maior que toda teorização acerca do processo educativo e de seus elementos constituintes. A escola, operando duas racionalidades, a teórica e a prática, apresenta-se, 
então, como lugar que articula, bem ou mal, adequada ou inadequadamente, os modos de pensar e os modos de fazer, entre o que se prescreve e se define e o que se faz e concretiza(porque movimento encarnado, contextualizado e materializado em ações). É neste lugar que a formação na docência define sua continuidade e seu aperfeiçoamento, tanto para os que dentro dela estão quanto para os que de fora a olham e a indagam(pesquisadores e avaliadores).

As pesquisas qualitativas indagam mais do que respondem, interrogam mais do que exclamam e tal perspectiva traz uma luminosidade epistemológica prenhe de conhecimentos que ultrapassam os portões escolares e os discursos oficiais. Conhecimentos que são produzidos, de certa forma, em parceria com os sujeitos da escola, entre-laçando concepções e práticas que dissipam certezas e impõem a constante reflexão do cotidiano escolar acerca da formação docente. Mas, em que consiste este cotidiano?

\section{O cotidiano escolar e os interstícios na formação docente}

A realidade escolar é complexa e plural, comportando um conjunto denso de elementos objetivos e condições subjetivas, materiais e imateriais. Cindida em tempos diversos (tempo do aprendizado, tempo dos sujeitos, tempo histórico-institucional) e constituída e constituinte de sujeitos co-partícipes do processo educativo. É nesta complexidade e pluralidade que a escola se concretiza em cotidiano, realizando a sua obra de educação. Heller (1994) destaca que é no cotidiano que a obra humana se realiza num sentido cumulativo e de continuidade permanente. Para para Hamel e Bauer (2009) a é importante estudar a obra humana enquanto produtora de alternativas de sobrevivência ao status quo.

Para Heller (1994), a vida cotidiana tem ideias provisórias, ações pragmáticas e utilidade que permitem ao ser humano reconhecer-se na própria ação, considerando que há uma dialética necessária de reelaboração do cotidiano entre rebeldia-dominação. Tal dialética é que possibilita a descotidianidade do espaço escolar. Tal descotidanidade é importante para que o cotidiano, cotidianizado, ou seja, não-refletido, não se converta em ações automatizadas de não-sujeitos e não autônomos em seu porvir.

O cotidiano escolar, contém, assim, elementos de preservação em ritos, rotinas, modos de fazer, contém fatores de fragmentação(seriação, turmas, disciplinas), de hierarquização (especialistas, professores, alunos, pais) e também apresenta grupos de 
oposição: atividades de resistência e subversão. A pesquisa do cotidiano escolar, segundo Duarte (2001) permite, assim, que se conheça a realidade da escola (movimento, preservação, provisoriedade), que se capte o significado do acontecimento (daquilo que causa desrupção no próprio cotidiano como indisciplina, violência, confrontos) e que se substancie planejamentos de ações de intervenção.

A centralidade do cotidiano nas pesquisas em educação, entendendo, neste texto, as pesquisas realizadas a partir de centros e grupos de pesquisa (universidades, especificamente) permite uma interlocução entre escola-universidade caracterizada por uma busca de sentidos. Pode-se, pois, inscrever tal interlocução como busca de sentidos, a saber: um sentido pessoal à formação; um sentido identitário à ação e um sentido coletivo ao saber-fazer docente.

Ao se focar no cotidiano escolar, escola e universidade, articulados, percorrem o caminho de um sentido pessoal que torna o experenciado por cada professor, um exercício pessoal de formação docente. Uma formação em que se institui a inquirição permanente, desfaz-se do senso-comum e entra-se numa zona de desconforto profissional que instiga o aperfeiçoamento, os significados das próprias ações cotidianas da docência.

Concomitante e este exercício de sujeito que se apropria de sua própria prática, possibilita-se a reinvenção e, por isso, fortalecimento, de um processo identitário, resignificado e revisto a partir da experienciação, ou seja, da reflexão acerca do próprio fazer e do ser que se reconstrói nesse movimento reflexivo docente.

Ao mesmo tempo que constitui-se re-conhecimento pessoal de um certo modo de se construir profissional na docência, oportuniza-se a sistematização do saber-fazer docente num sentido de colegialidade, em que os pares compartilham seus saberes e não-saberes, desvelam suas práticas e reelaboram as teorias.

Garante-se, assim, a ocorrência da circularidade do conhecimento docente, em que uma prática, apoiada numa teoria, se resignifica na própria prática, modificando esta mesma prática, num salto qualitativo via discussão e reflexão. É esta circularidade que define e justifica a importância de grupos de trabalho entre professores da escola e pesquisadores(e professores) da universidade.

Um grupo de trabalho, enfatizando as práticas de ensino baseadas na Pedagogia da Autonomia (Grupo de Trabalho sobre a Pedagogia da Autonomia- GTPA) reveste-se, em seus meandros, de uma configuração circular entre saberes legitimados pela teoria e saberes advindos da experiência docente, assumindo a centralidade do cotidiano como 
categoria de investigação-prática. Não há, nesta configuração, um protagonismo praxiológico nem o foco num estudo puramente teórico. Há sim como ponto de partida e de chegada a prática, consubstanciada em reflexões, discussões e apreciações de um grupo de professores, atuantes na Universidade e nas escolas da Educação Básica(Fundamental II e Ensino Médio).

\section{O cotidiano escolar na articulação universidade-escola e na formação docente}

Por meio de um grupo híbrido de professores e licenciandos do Ensino Superior e professores da Educação Básica oportuniza-se um tipo de formação docente apoiada em seu contexto profissional, em que o cotidiano escolar se desvela e se rearranja a partir de um exercício consubstanciado no compartilhamento teórico-prático docente.

As situações aqui pontuadas advém de registros dos encontros mensais entre 30 professores e licenciandos (este número varia para mais ou para menos, conforme cada encontro em questão), entre março-2013 e junho de 2015. Optou-se por manter o anonimato dos professores e licenciandos para preservar a sua coragem de expor suas práticas e suas reflexões para outros professores. Ademais, o objetivo deste estudo é de refletir acerca do lugar da pesquisa no/do cotidiano escolar na (auto) formação docente.

Observa-se que grupos como estes retiram o isolamento dos pesquisadores, desinstalando-os do Ensino Superior ao se aproximarem das escolas, potencializando o seu lugar privilegiado de sentidos que são construídos na formação e autoformação docente. Ou seja, um grupo que se movimenta no estudo do cotidiano a fim de descotidianizá-lo à luz da Pedagogia da Autonomia e por meio de compartilhamento e reflexão de saberes e fazeres docentes.

Certeau (1994) destaca que, sobre o risco de automatização da cotidianidade, há necessidade de se compreender que o homem ordinário escapa à conformação e inventa o cotidiano, criando sua própria maneira de fazer e apropriar-se das práticas. É o que o autor denomina de teoria das práticas.

Estas práticas cotidianas, segundo Certeau(1994), podem ser estratégicas ou táticas. As estratégias correspondem ao que está legitimado, posto, registrado e reconhecido como tais, enquanto a prática tática ainda não tem lugar, porque não são conhecidas e, por isso, não podem ser reconhecidas. A interlocução escola-universidade pode se constituir um espaço fértil de descotidianidade (HELLER, 1994) em que as 
práticas estratégicas sejam revistas a partir das evidências teórico-práticas de uma docência que se realiza no cotidiano.

Há, nesta interlocução escola-universidade, pela via da descotidianidade escolar:

a- um processo paulatino de individuação da formação e de seus percursos, em que os professores assumem seu modo próprio de exercer a professoralidade, reconhecendo atividades docentes que se sofisticam em significados, ao mesmo tempo em que teorias são buscadas para auxiliar na compreensão dos fazeres. Este é o caso de um professor, integrante do GTPA, que registra suas aulas em um blog que é disponibilizado para o grupo e para seus próprios alunos e ali se gera um espaço de discussão sobre o que se estuda, o que se pesquisa e o que se aprende nas aulas de matemática;

b- a inserção de sentimentos/emoções/vocações que se mesclam aos estudos e aos compartilhamentos de experiências docentes, advindas de outros canais que são percorridos em função das necessidades postas pelas próprias discussões porque nem sempre a teoria basta para a compreensão das práticas e de seus efeitos. Pode-se perceber esse movimento no GTPA quando uma professora, ao discutir a questão do professor e seus sentimentos, sugere a discussão sobre um filme para subsidiar o compartilhamento e reflexão sobre a temática. Assim, a partir disto, a discussão de filmes tornou-se um dos percursos do próprio grupo, tendo, a cada encontro mensal, um filme em sua agenda;

c- religação de posturas, leituras de mundo que se alargam pela confluência de diferentes olhares acerca do vivido no cotidiano escolar, evidenciando coincidências de cenários entre Educação Básica e Ensino Superior. Professores universitários compartilhando práticas desenvolvidas e adaptadas de práticas docentes apresentadas e discutidas por professores da Educação Básica e viceversa como uso de determinados recursos tecnológicos digitais como infográficos, grupos de discussão em rede, etc;

d- coreografia coletiva/problemáticas comuns que se instalam e se desinstalam de seus formatos originais e se misturam em projetos comuns que são propostos em 
escolas diferentes com resultados semelhantes trazidos para compartilhamento mensal como um projeto que está sendo realizado, envolvendo alunos de escolas variadas de Educação Básica(pública e privada) e Ensino Superior(público e privado), sob a coordenação de professores do GTPA.

Observa-se que a pesquisa se faz a partir do compartilhamento e do relato e, por conseguinte, promove o distanciamento do cotidiano escolar permitindo:

$\checkmark$ Um olhar mais cuidadoso quanto ao que se pensa e se faz na prática docente, assumindo uma postura investigativa sobre as práticas. É quando uma professora da Educação Básica compartilha uma experiência em andamento usando uma ferramenta digital (infográficos) e solicita, dois meses depois, um momento para discutir os resultados do trabalho a partir de suas reflexões, a posteriori, carregadas de autocrítica;

$\checkmark$ A apreensão do erro como possibilidade concreta de redefinição das ações docentes, como um professor de matemática que reelabora seu pensar sobre o "não-significado" de uma proposta de aula nas montanhas sem um objetivo que desse sentido à própria proposta ou que não fosse apenas o fato de deslocar os alunos e inseri-los em outro cenário;

$\checkmark$ A criação de um espaço de reflexão coletiva para além do próprio grupo de pesquisa, instalando-se em cada escola de cada professor participante do grupo. São relatos de professores, integrantes do grupo contando como as conversas com seus colegas no intervalo de aulas tem se convertido em discussões parecidas com o que acontece mensalmente no GTPA;

$\checkmark$ A sistematização do estudo sobre a própria prática, em que anotações são feitas após cada dia de trabalho. Um exercício de registro que os professores do grupo dizem estar se tornando uma ação diária após as aulas;

$\checkmark$ O melhor enfrentamento do conflito, em que a argumentação torna-se adequadamente densa e relatada orgulhosamente no grupo em situações pontuais na escola em que trabalham como o posicionamento que assumem em reuniões pedagógicas em suas escolas; 
$\checkmark$ A postura ética resultante do próprio exercício da reflexão permanente acerca do cotidiano descotidianizado, quando vai se construindo um criterioso processo de tomada de decisão, conforme relatado por um docente de História, na escolha de um autor, de um texto ou de um material audiovisual para suas aulas. O mesmo cuidado também foi relatado por alunos em situação de estágio, quando preparam suas aulas.

Assim, os professores, ao se afastarem de seu cotidiano, desfamiliarizando-se do espaço e tempo escolares, desenvolvem competências de pesquisadores para além da própria prática docente.

Ao se instituir o cotidiano escolar no itinerário de estudos de um grupo de professores pode-se, pois reconhecer os saberes das práticas e das teorias já consolidadas e reconhecidas, bem como identificar os fazeres que se repetem e permanecem bem como os que se conectam com um caráter de inovação ou com processos de intervenção. É um modo de imersão pedagógica no sentido de transformar o cotidiano escolar pela problematização, pois instala-se um olhar docente que inquiri, problematiza, enfrenta e reelabora.

Ao se problematizar a prática docente no cotidiano escolar, descotidianizam-se as práticas docentes como ações estratégicas, constroem-se novas experiências a partir das ações táticas docentes e garante-se a articulação entre teoria-prática resignificada pela práxis.

\section{Considerações finais}

Ao assumir o cotidiano escolar como objeto pesquisa, professores se formam e se autoformam na docência numa experiência coletiva de compartilhamento (mas não só) de prática (mas não só). $\quad$ O estudo do cotidiano escolar neste trabalho reflexivo acerca de um grupo de trabalho sobre a Pedagogia da Autonomia:

$\checkmark$ Mostra-se um método para o aprendizado permanente do próprio saber-fazer docente;

$\checkmark$ Apresenta-se como um dispositivo pedagógico característico de contextualização de reflexões e teorias acerca da docência; 
$\checkmark$ Indica um caminho para a construção coletiva de conhecimento pedagógico;

$\checkmark$ Evidencia a possibilidade de criação de mecanismos de sistematização da procura e da construção de conhecimento docente.

Enfim, tais indícios apontam a fertilidade do cotidiano escolar como suporte para a materialização de uma pedagogia com vistas à autonomia e como elemento inconteste que pode garantir a articulação universidade-escola, derrubando muros hierárquicos de professores pesquisadores e não-pesquisadores, tornando-os parceiros e co-construtores de outros saberes e fazeres que resignificam o cotidiano escolar.

Cabe destacar que a centralidade do cotidiano escolar na articulação escolauniversidade provoca o sentido da própria pesquisa como forma de garantir a (auto) formação continuada docente. Não uma pesquisa carregada de todo o rigor exigido à pesquisa científica, mas um modo de investigar a própria prática e fazer, da inquirição ao cotidiano escolar, um caminho para escolhas didático-pedagógicas, para estudos teórico-metodológicos, para a autocrítica e para práticas mais reflexivas de professores tanto os que atuam na docência superior e na Educação Básica. Suas áreas de conhecimento se des-hierarquizam e as particularidades são mantidas, porém ocorre a instauração paulatina da práxis como elemento-formador da própria docência.

\section{Referências}

ALVES, Nilda. Sobre movimentos das pesquisas nos/dos/com os cotidianos. Revista Teias, Rio de Janeiro, ano 4, nº 7-8, jan/dez 2003.

ANDRÉ, Marli E. D. A. Cotidiano escolar e práticas sócio-pedagógicas. Em Aberto, Brasília, ano 11, n.53, jan/mar. 1992

CANDAU, Vera Maria F. Diferenças culturais, cotidiano escolar e práticas pedagógicas. Currículo sem Fronteiras, v.11, n.2, pp.240-255, Jul/Dez, 2011.

CERTEAU, Michel de. A invenção do cotidiano - artes de fazer. Petrópolis: Vozes, 1994.

DUARTE, Newton. Educação escolar, teoria do cotidiano e a escola de Vygotski. 3a ed. Campinas, Autores Associados, 2001(Coleção Polêmicas do Nosso Tempo, v. 55)

HELLER, A. Sociologia de la vida cotidiana. 4. ed. Barcelona: Península, 1994.

HAMEL, Thérese e BAUER, Carlos. Do sabor do giz e do quadro negro, da professora e das crianças, que tomam seu destino nas próprias mãos. In. DAL MAS DIAS, Elaine 
T. e LORIERI, Marcos Antonio(orgs). Teorias e políticas em educação. São Paulo, Xamã, 2009.

NUNES, Célia Maria Fernandes. Saberes docentes e formação de professores: um breve panorama da pesquisa brasileira. Educação \& Sociedade, ano XXII, nº 74, Abril/2001

POPKEWITZ, Thomas. Números em grades de inteligibilidade: dando sentido à verdade educacional. In. TURA, Maria de Lourdes R e GARCIA, Maria Manuela A. Currículo, políticas e ação docente. RJ, Ed. Uerj, 2013, 19-50.

STANO, Rita de Cássia Magalhães Trindade. A pesquisa do cotidiano escolar pelas trilhas da formação docente: uma articulação universidade-escola. Revista IberoAmericana de Estudos em Educação, Araraquara, v.12, n.1, p. 529-540, 2017. Disponível em: <http://dx.doi.org/10.21723/riaee.v12.n1.8156.1>. E-ISSN: 1982-5587.

Data de submissão: out/2015

Aprovação final: fev/17 